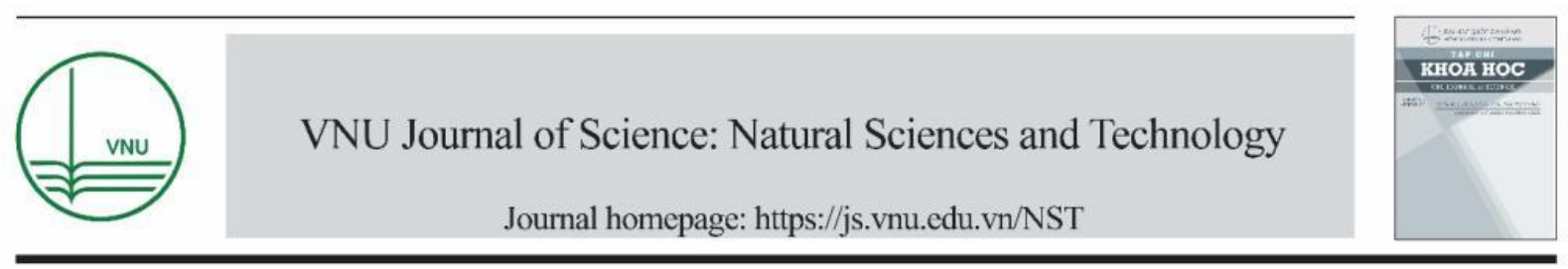

Original Article

\title{
In Silico Analysis of Osa-miR164 Gene Family in Rice (Oryza Sativa)
}

\author{
Vuong Quang Tien ${ }^{1, \mathrm{a}}$, Nguyen Huy Duong ${ }^{2, \mathrm{~b}}$, Nguyen Lam Phuc ${ }^{1}$, \\ Phan Minh $\mathrm{Vu}^{1}$, Dao Trong Nhan ${ }^{1}$, Do Thi Phuc ${ }^{1, *}$ \\ ${ }^{I}$ VNU University of Science, 334 Nguyen Trai, Thanh Xuan, Hanoi, Vietnam \\ ${ }^{2}$ Vietnam Academy of Science and Technology, 18 Hoang Quoc Viet, Cau Giay, Hanoi, Vietnam
}

Received 12 August 2021

Revised 06 September 2021; Accepted 06 September 2021

\begin{abstract}
MicroRNA (miRNA) is a small ( 22 nucleotides) non-coding RNA molecule, which functions in post-transcriptional regulation of gene expression. Previous reports have shown that miRNA plays an important role in the resistance ability of plants to adverse conditions. In this research, we focused on miR164 family in rice (Oryza sativa), a major food crop. By using bioinformatics approach, we analyzed sequences of all osa-miR164s belonging to rice miR164 family, evaluated the expression profile of osa-miRl64 under different stress conditions, predicted cis-regulatory elements on osa-miRl64 gene promoters, and simultaneously predicted miR164-targeted genes and their expressions. The results show high conserve in mature osa-miR164 sequences but not in the precursor sequences, different expression patterns of osa-miRl64 gene members under stress conditions and various cis-regulatory elements present in osa-miRl64 gene promoters, which might explain the diverse expression patterns of osa-miR164 genes. Some potential target genes of osa-miR164 were identified and their expressions under different stress conditions were analyzed.
\end{abstract}

Keywords: miR164, microRNA, non-coding RNA, rice, Oryza sativa.

\section{Introduction}

MicroRNAs are small non-coding RNA molecules containing about 22 nucleotides that function in post-transcriptional regulation of gene expression [1]. miRNAs play key roles in animals and plants, by promoting cleavage or translation inhibition of targeting mRNAs [1].

\footnotetext{
${ }^{\mathrm{a}, \mathrm{b}}$ These authors contributed equally to this work.

* Corresponding author.

E-mail address: dothiphuc@hus.edu.vn

https://doi.org/10.25073/2588-1140/vnunst.5304
}

Lin-4 was the first miRNA detected in Caenorhabditis elegans [2], and in plant, early miRNAs were detected in Arabidopsis thaliana [3]. miRNAs negatively regulate mRNA by guiding the cleavage while being active in RISC complex (RNA-induced silencing complex) and suppressing protein synthesis or degrading targeting mRNAs [4].

MiR164 family in plants consists of miRNAs with conserved sequences which were found in several species and were one of the first cloned miRNAs in Arabidopsis [3] In Arabidopsis, miR164s mark cleavage site of mRNAs 
corresponding with targeting NAC genes [NAC genes include: no apical meristem (NAM), Arabidopsis transcription activation factor (ATAF) and cup-shaped cotyledon (CUC)] [5]. In Arabidopsis, miRNA164 family has 3 members (ath-miR164a/b/c) which target five NAC genes (CUC1/At3g15170, CUC2/At5g53950, NAC1/At1g56010, At5g07680, and At5g61430). Some studies showed that these NAC genes are required for lateral root development, expansion of the boundary domain, regulation of the age-dependent cell death, and formation of vegetative and floral organs [6-8].

In rice, there are 6 gene members in miR164 family, consisting of osa-miR $164 \mathrm{a} / \mathrm{b} / \mathrm{c} / \mathrm{d} / \mathrm{e} / \mathrm{f}$ [9]. It is suggested that miR164-targeted NAC (OMTN) genes may act as negative regulators of drought tolerance in rice with overexpression of OMTN2, OMTN3, OMTN4, and OMTN6 caused increased drought sensitivity in transgenic plant [10].

In this study, we aim to investigate the rice miR164 genes and their targets in response to stress conditions by employing the bioinformatic approach to research on expression profile of osa-miR164 genes under different stress treatments, expression regulation of osa-miR614 genes by cis-regulatory elements present in gene promoters, and miR164-targeted genes' expressions under different stresses.

\section{Methodology}

\subsection{Genomic Analysis}

All stem-loop, mature sequences and locations of osa-miRl64 family were obtained from the miRBase database (http://www.miRBase.org/) [11]. These sequences were aligned by CLUSTALW [12] using MEGA7 [13].

\subsection{Identification of Potential Promoters of Osa-miR164s}

For promoter prediction, the upstream sequences pre-microRNAs of each osa-miRl64 gene were downloaded from the rice genome database (http://rice.plantbiology.msu.edu/). The $1500 \mathrm{bp}$ sequence of 5 ' to the pre-miRNA was retrieved as the promoter region. The TSSs (Transcription Starting Site) were predicted by the YAPP Eukaryotic core promoter predictor (http://www.bioinformatics.org/yapp/cgi-

bin/yapp.cgi), a tool to scan for canonical core promoter elements - BREs (B recognition element), TATA boxes, INRs (initiator motif) and DPEs (downstream promoter element), and synergistic combinations of these elements. The obtained promoters were the ones closest to the 5' of the pre-miR164.

\subsection{Analysis of Cis-regulatory Elements of Rice Osa-miR164 Family}

Potential promoter regions (the $1500 \mathrm{bp}$ of 5 ' region upstream of the pre-miRNAs) were used to predict the cis-regulatory elements and motifs. The SOGO NEW PLACE database (https://sogo.dna.affrc.go.jp/cgi-

bin/sogo.cgi?lang=en), a Database of Plant Cis-acting Regulatory DNA Elements, was used to analyze the cis-regulatory elements of the osa-miR164 family.

\subsection{Genes Target Prediction and Their Functions}

Mature osa-miRl64 sequences of Oryza sativa were downloaded from miRBase. The target genes of osa-miR164a/b/c/d/elf were identified by using psRNATarget (Version 2017) with the default parameters input, except a more stringent cut-off threshold of expectation $\leq 2$. The RAP-DB database was used to confirm the information of targeted genes. Uniprot database was used to determine functions of osa-miR164 targeted genes.

\subsection{Expression of Osa-miR164 in Abiotic Stress Conditions}

The expression profiles of osa-miR164a/b/c/d/elf were extracted from PmiRExAt@NABI database [14]. The relative expression level of the gene was presented as the $\log 2$ fold change between the control conditions and the different treatments or stress conditions. 
2.6. Expression of Osa-miR164 Targeted Genes under Abiotic and Biotic Stresses

To show the expression level of targeted genes under abiotic and biotic stresses, online TENOR and RiceXPro databases were employed to get data experiments under stress conditions of osa-miRl64 targeted genes.

\section{Results and Discussion}

\subsection{Sequence Comparison of Osa-miR164 Gene Family}

Based on miRBase database, there are six genes in rice miR164 family, including osa-miRl64a, osa-miR164b, osa-miR164c, osa-miR164d, osa-miR164e, osa-miR164f.
Osa-miRl64a osa-miR164b, osa-miR164c, osa-miR164d, osa-miRl64e, osa-miRl64f, locate in Chr7: 28523341-28523496, Chr5: 15896163-15896271, Chr5: 17327440-17327558, Chr2: 33143567-33143660, Chr3: $10542157-$ 10542288 and Chr5: 23343908-23344117, respectively. Mature sequences of osa-miRl64a, osa-miR164b, osa-miRl64f are $100 \%$ identical (Figure 1A). However, osa-miRl64c and osa-miRl64d have one different nucleotide from osa-miR164a, $b, f$ $\left(14^{\text {th }}\right.$ base of $o s a-m i R 164 c$ is $\mathrm{U}$, and $21^{\text {st }}$ base of osa-miRl64d is U), and osa-miRl64e has 2 different nucleotides $\left(20^{\text {th }}\right.$ base is $\mathrm{A}$ and $21^{\text {st }}$ base is $\mathrm{G})$ (Figure 1A).

A
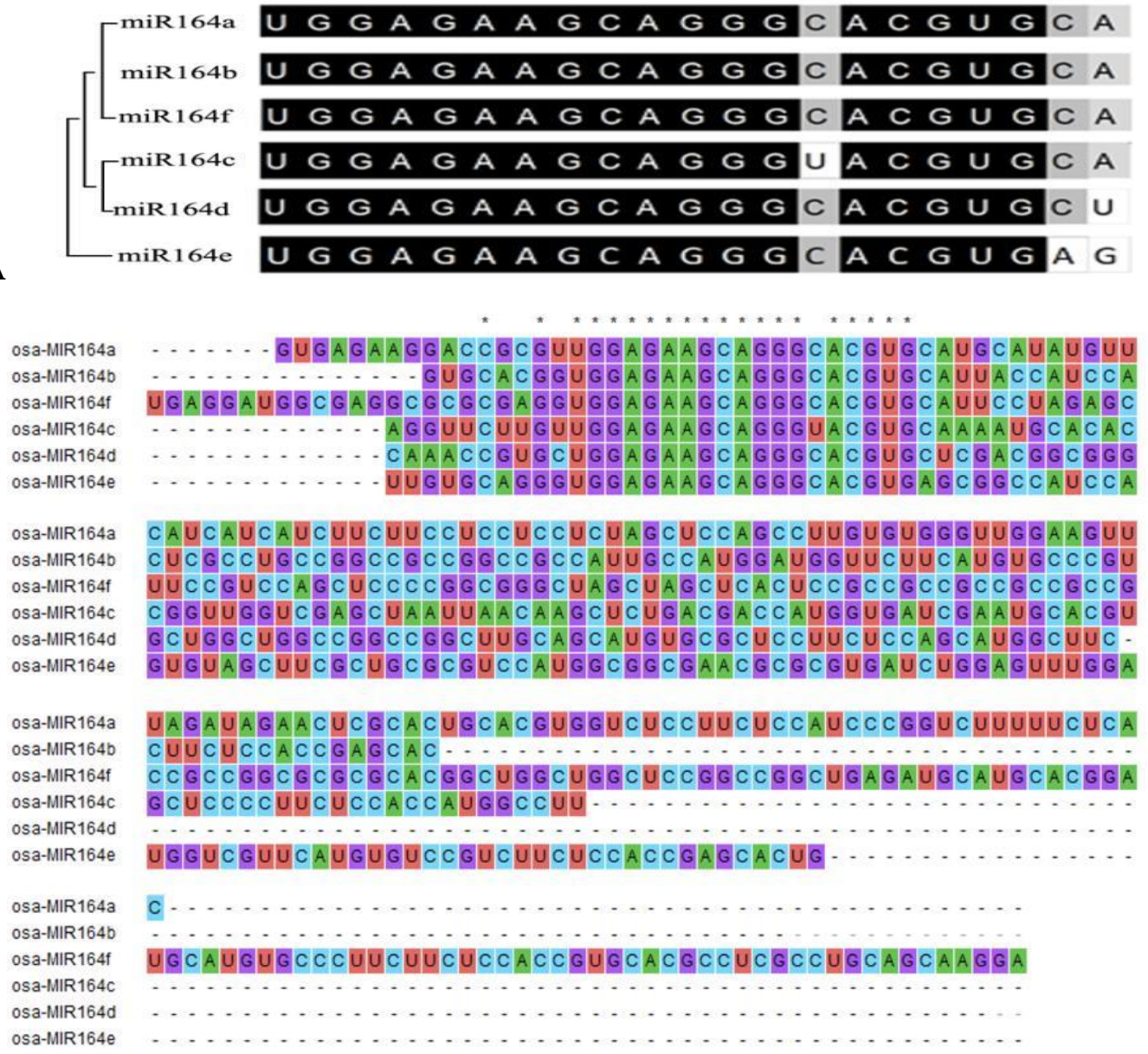

Figure 1. A - Alignment of the mature osa-miR164 sequences in rice. Black color indicates identical nucleotides among six osa-miR164s, while fading ones show lower similarity among six osa-miR164s. B - Alignment of the precursor osa-miRl64 sequences. Asterisk marks identical nucleotide. 
Since the sequences of mature $o s a-m i R 164 s$ are highly conserved, we further analyze the sequences of osa-miRl64 precursors. The results show that the osa-miR164 precursor sequences were completely different (excluding mature sequences). They shared only 1 nucleotide $\mathrm{C}\left(5^{\text {th }}\right.$ base upstream mature sequences) and 1 nucleotide $\mathrm{G}\left(2^{\text {nd }}\right.$ base upstream mature sequences) (Figure 1B).

\subsection{Analysis of Cis-regulatory Elements of Osa-miRl64 Gene Promoters}

The cis-regulatory elements present in osa-miR164 gene promoters are shown in Figure 2 and Table 1. MYC, MYB and CuRe motifs (involved in response to abscisic acid, regulation of drought and copper, respectively) are common and can be found in all genes in large numbers, indicating that miRl64 gene family is highly regulated by drought, abscisic acid and copper conditions. DRE motif (salt/drought response) was common in $o s a-m i R 164 c$ and osa-miR164f genes. They are found at the distal part of 5 ' regulatory region in osa-miR164c whilst spread across the
osa-miRl64f gene. SuRe motif (sulfur responsive element) was found in all genes in small amounts, whereas Erd-1 (required for early response to dehydration) was found in all the regulatory regions of the osa-miRl64 genes at varying frequencies. LTRE (Low temperature responsive element) was only distributed in $o s a-m i R 164 b, c, f$. I-box and ASF-1 motif (light regulation element) were widespread in all regulatory regions. Sugar-repressive elements (TATCCAY, A-box, Pyrimidine box, GARE) were distributed differently between six genes, in which they were absent in osa-miR164e. GARE motif was found in osa-miRl64d and osa-miR164f whereas A-box was present only in osa-miR164f. Regarding hormone related cis-regulatory elements, ABRE motif (abscisic acid responsive element) was found in 5 genes except osa-miR164b. S-box (important in ABA response) was located only in osa-miR164c. ARF (auxin response) was presented at varying frequencies in all genes and highest in osa-miR164f (Figure 2).

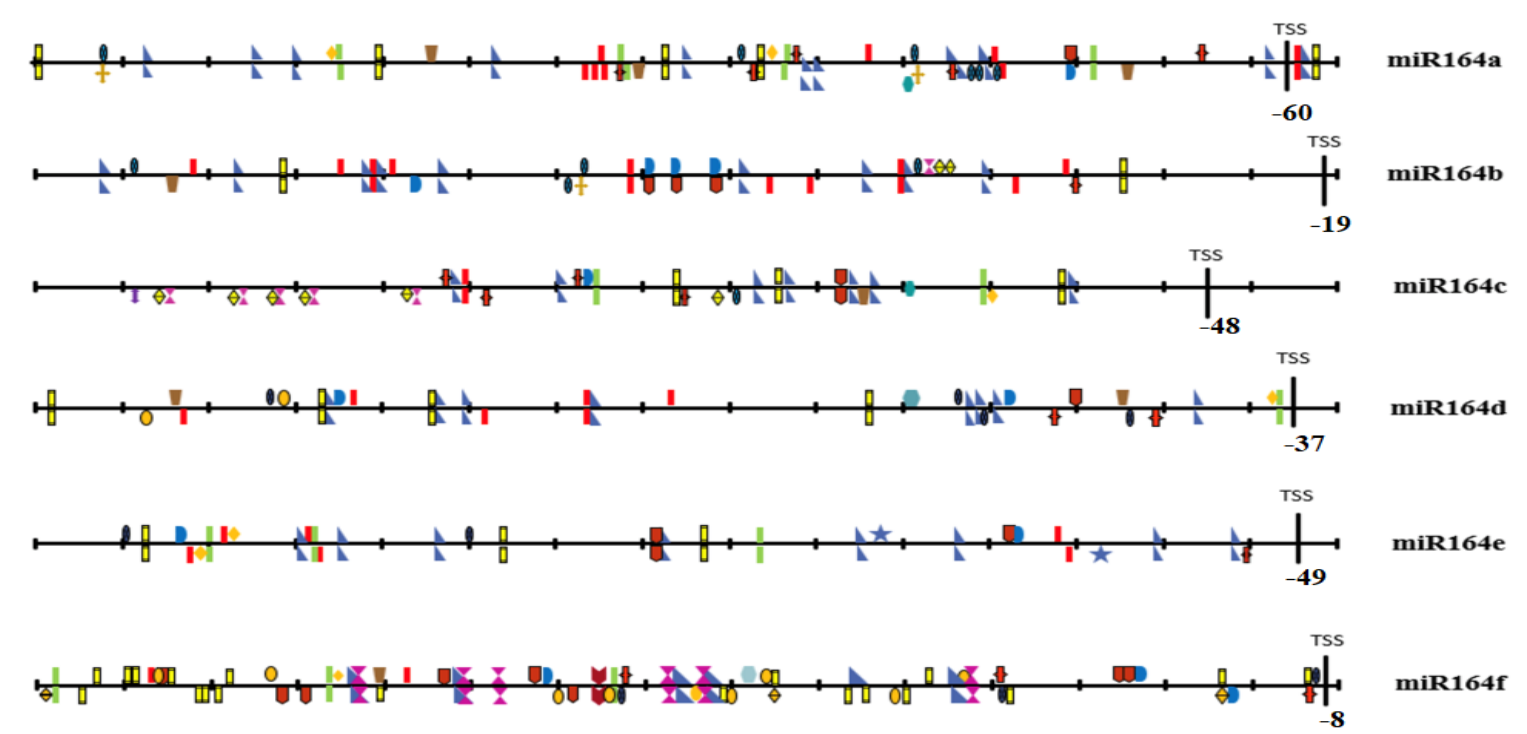

Figure 2. Map of promoter regions of $o s a-m i R 164$ genes. The corresponding cis-regulatory elements are described in Table 1. Position of transcription start side (TSS) is predicted using YAPP database.

The first nucleotide of $o s a-m i R 164$ precursors is considered as +1 . 
Table 1. Potential cis- regulatory elements identified in the 5' regulatory sequences of osa-miRl64 gene family.

The $1.5 \mathrm{~kb}$ of 5 ' regulatory region was analyzed using PLACE and YAPP databases

\begin{tabular}{|c|c|c|c|c|c|c|c|c|c|c|}
\hline \multirow{2}{*}{$\begin{array}{l}\text { Cis-regulatory } \\
\text { elements }\end{array}$} & \multirow{2}{*}{ Sequence } & \multirow{2}{*}{ Symbol } & \multirow{2}{*}{ Function } & \multirow{2}{*}{ Reference } & \multicolumn{6}{|c|}{ MiR164 } \\
\hline & & & & & a & $\mathrm{b}$ & $\mathrm{c}$ & $\mathrm{d}$ & $\mathrm{e}$ & $\mathrm{f}$ \\
\hline DRE & A/GCCGAC & $\mathbf{B}$ & $\begin{array}{l}\text { Salt/drought response } \\
\text { element }\end{array}$ & [15] & 0 & 1 & 5 & 0 & 0 & 12 \\
\hline ABRE & $\begin{array}{l}\text { (C/A)ACG } \\
(\mathrm{T} / \mathrm{C}) \\
\mathrm{G}(\mathrm{T} / \mathrm{C} / \mathrm{G})\end{array}$ & & $\begin{array}{l}\text { Abscisic acid response } \\
\text { element }\end{array}$ & [16] & 2 & 0 & 1 & 1 & 2 & 1 \\
\hline MYC & $\begin{array}{l}\text { CATGTG; } \\
\text { CACATG; } \\
\text { CANNTG }\end{array}$ & & $\begin{array}{l}\text { Early response to drought } \\
\text { and abscisic acid } \\
\text { induction }\end{array}$ & [17] & 22 & 18 & 14 & 20 & 22 & 17 \\
\hline GARE & $\begin{array}{l}\text { TAACAA } \\
\text { (G/A) }\end{array}$ & & $\begin{array}{l}\text { Gibberellin Responsive } \\
\text { element }\end{array}$ & [16] & 0 & 0 & 0 & 4 & 0 & 9 \\
\hline CuRE & $\begin{array}{l}5^{\prime}-\mathrm{TTTGC} \\
\text { (T/G)C(A/G)-3' }\end{array}$ & & $\begin{array}{l}\text { Copper responsive } \\
\text { element and also } \\
\text { involved in oxygen } \\
\text { response }\end{array}$ & [18] & 10 & 4 & 6 & 8 & 10 & 19 \\
\hline SuRE & GAGAC & & $\begin{array}{l}\text { Sulphur responsive } \\
\text { element }\end{array}$ & [19] & 1 & 4 & 1 & 2 & 2 & 3 \\
\hline $\mathrm{ARF}$ & $\begin{array}{l}\text { GGTCCAT; } \\
\text { TGTCTC }\end{array}$ & & Auxin response element & [16] & 1 & 3 & 2 & 1 & 3 & 8 \\
\hline MYB & $\begin{array}{l}\text { WAACCA; } \\
\text { TAACTG; } \\
\text { CNGTTR; } \\
\text { YAACKG; } \\
\text { GGATA; } \\
\text { CAACTG }\end{array}$ & & $\begin{array}{l}\text { Involved in regulation of } \\
\text { drought }\end{array}$ & [20] & 9 & 13 & 2 & 7 & 6 & 2 \\
\hline Erd 1 & ACGT & & $\begin{array}{l}\text { Early response to } \\
\text { dehydration }\end{array}$ & [15] & 8 & 0 & 4 & 2 & 8 & 6 \\
\hline Pyrimidine box & $\begin{array}{l}\text { TTTTTTCC; } \\
\text { ССТTTT }\end{array}$ & & $\begin{array}{l}\text { Gibberellin-response } \\
\text { cis-element }\end{array}$ & [21] & 3 & 1 & 1 & 2 & 0 & 1 \\
\hline $\begin{array}{l}\text { TATCCAY } \\
\text { motif }\end{array}$ & TATCCA & & $\begin{array}{l}\text { Involved in sugar } \\
\text { repression }\end{array}$ & [22] & 1 & 0 & 1 & 1 & 0 & 1 \\
\hline SRE & TTATCCA & & Sugar-repressive element & [19] & 2 & 1 & 0 & 0 & 0 & 0 \\
\hline LTRE & $\begin{array}{l}\text { ACCGACA; } \\
\text { CCGAAA; } \\
\text { GTCGAC }\end{array}$ & & $\begin{array}{l}\text { Low temperature } \\
\text { responsive element }\end{array}$ & {$[23]$} & 0 & 2 & 6 & 0 & 0 & 3 \\
\hline A-box & TACGTA & & Sugar repression element & [24] & 0 & 0 & 0 & 0 & 0 & 2 \\
\hline S-box & $\begin{array}{l}\text { CACCT(C/T) } \\
(\mathrm{C} / \mathrm{T}) \mathrm{A}\end{array}$ & & Sugar and $\mathrm{ABA}$ response & {$[25]$} & 0 & 0 & 1 & 0 & 0 & 0 \\
\hline CMSRE-1 & TGGACGG & & $\begin{array}{l}\text { Carbohydrate Metabolite } \\
\text { Signal Response }\end{array}$ & [26] & 0 & 0 & 0 & 0 & 2 & 0 \\
\hline ASF-1 motif & TGGACG & & $\begin{array}{l}\text { Relevant to light } \\
\text { regulation. }\end{array}$ & [27] & 5 & 1 & 4 & 2 & 1 & 3 \\
\hline I-box & GATAAG & 0 & Light box Element & [28] & 6 & 4 & 1 & 4 & 2 & 3 \\
\hline
\end{tabular}




\subsection{Identification of Oa-miR164 Targeted Genes}

Nine osa-miRl64 targeted genes were predicted by using psRNATarget, including NAC-domain proteins (OMTN1-OMTN6), BURP domain protein 4 (OsBURP 4), proteophosphoglycan ppg4 and LOC_Os03g47310. (Table 2). Five genes (OMTN1-OMTN5), BURP domain-containing protein 4 (OsBURP04) and proteophosphoglycan ppg4 are regulated by all six osa-miRl64 genes. The other genes (OMTN 6 and LOC_Os03g47310) are regulated by five of osa-miR164s, except osa-miR164c. Functions of osa-miRl64 targeted genes are identified by using UniProt database, except OsBURP04, proteophosphoglycan ppg4 and LOC_Os03g47310 that cannot identify the functions (Table 2).

Table 2. Potential target genes of osa-miR164 genes with their IDs and functions

\begin{tabular}{|c|c|c|c|c|}
\hline Micro RNA & Target genes ID & Target genes name & $\begin{array}{l}\text { Target gene } \\
\text { function }\end{array}$ & Previous research \\
\hline \multirow{7}{*}{$\begin{array}{l}\text { Osa-miR164a } \\
/ \mathrm{b} / \mathrm{c} / \mathrm{d} / \mathrm{e} / \mathrm{f}\end{array}$} & LOC_Os02g36880 & NAC1 $(O M T N 1)$ & \multirow{5}{*}{$\begin{array}{l}\text { Controls the rate of } \\
\text { transcription of } \\
\text { genetic information } \\
\text { from DNA to } \\
\text { mRNA, by binding } \\
\text { to a specific DNA } \\
\text { sequence }\end{array}$} & \multirow{5}{*}{$\begin{array}{l}\text { Expression of } \\
\text { OsNAC family } \\
\text { genes in drought } \\
\text { stress [10] }\end{array}$} \\
\hline & LOC_Os04g38720 & OMTN2 & & \\
\hline & LOC_Os12g41680 & OMTN3 & & \\
\hline & LOC_Os06g46270 & OMTN4 & & \\
\hline & LOC_Os06g23650 & OMTN5 & & \\
\hline & LOC_Os02g18690 & $\begin{array}{l}\text { BURP domain-containing } \\
\text { protein } 4\end{array}$ & $\begin{array}{l}\text { Expressed } \\
\text { in stamen }\end{array}$ & $\begin{array}{l}\text { Identify BURP } \\
\text { domain- } \\
\text { containing genes } \\
\text { and response } \\
\text { levels to abiotic } \\
\text { stresses [29] }\end{array}$ \\
\hline & LOC_Os09g37700 & proteophosphoglycan ppg 4 & $\begin{array}{l}\text { Flowering related } \\
\text { gene in wild rice }\end{array}$ & $\begin{array}{l}\text { Expression } \\
\text { profiles of the } \\
\text { flowering related } \\
\text { genes in common } \\
\text { wild rice [30] } \\
\end{array}$ \\
\hline \multirow[t]{2}{*}{$\begin{array}{l}\text { Osa-miR164 } \\
\text { a/b/d/e/f }\end{array}$} & LOC_Os08g10080 & OMTN6 & $\begin{array}{l}\text { Controls the rate } \\
\text { of transcription of } \\
\text { genetic information } \\
\text { from DNA to } \\
\text { mRNA, by binding } \\
\text { to a specific DNA } \\
\text { sequence }\end{array}$ & $\begin{array}{l}\text { Expression of } \\
\text { OsNAC family } \\
\text { genes in drought } \\
\text { stress [10] }\end{array}$ \\
\hline & LOC_Os03g47310 & & $\begin{array}{l}\text { transposon protein, } \\
\text { putative, CACTA, } \\
\text { En/Spm sub-class }\end{array}$ & $\begin{array}{l}\text { Locates in QTLs } \\
\text { for } \mathrm{Zn}, \mathrm{Fe}, \mathrm{Al} \\
\text { toxicity tolerance } \\
\text { in rice }[31,32]\end{array}$ \\
\hline
\end{tabular}




\subsection{Expression Levels of Osa-miR164 Genes in Several Abiotic Stresses}

As shown in Figure 3, the expression patterns of $o s a-m i R 164$ genes were diverse in response to stresses. While osa-miR164c decreased in expression level, other osa-miRl64a/b/f/d expression levels showed slightly increase in all stress conditions. The osa-miR164e changed its expression level differently between stress conditions, in which it decreased under drought and salt conditions while slightly increased under cold treatment.

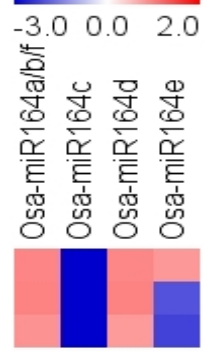

\section{Cold stress 14 days Drought stress 14 days Salt stress 14 days}

Figure 3. Heatmap representing expression level of $o s a-m i R 164 s$ in several abiotic stresses.

\subsection{Expression Levels of Osa-miR164 Targeted Genes in Different Stress Conditions}

The expression profiles of eight
osa-miRl64 targeted genes except LOC_Os03g47310 gene in the shoot and the root under different stress conditions were obtained in TENOR and RiceXPro databases and were visualized as heatmap in Figure 4.

The gene expression in the roots was shown in Figure 4A. In the NAC gene family (OMTN1-OMTN6) OMTN1 up regulated in all stress conditions and showed highest under osmosis, ABA and JA stresses; OMTN5 also up regulated in almost all stress conditions, except after $3 \mathrm{~h}$ of dry treatment; OMTN4 had slightly changes in expression levels; OMTN3 down regulated under dry, cold, osmotic stress $\mathrm{ABA}$ and JA treatments, but up regulated under high salinity and flood conditions; and OMTN6 down regulated in all stress conditions. OsBURPO4 up regulated in all stress conditions, whilst $P P G 4$ down regulated in most of stress conditions, except in high salinity.

A)

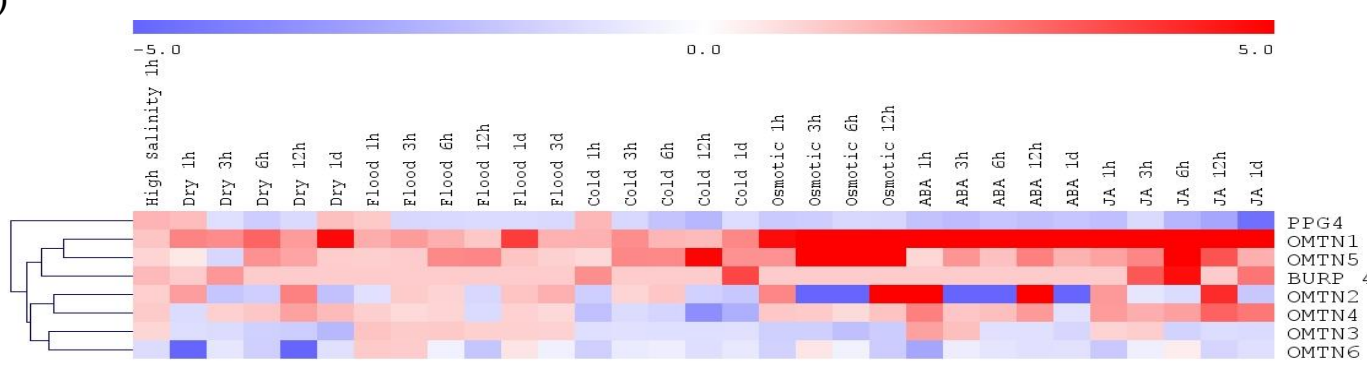

B)

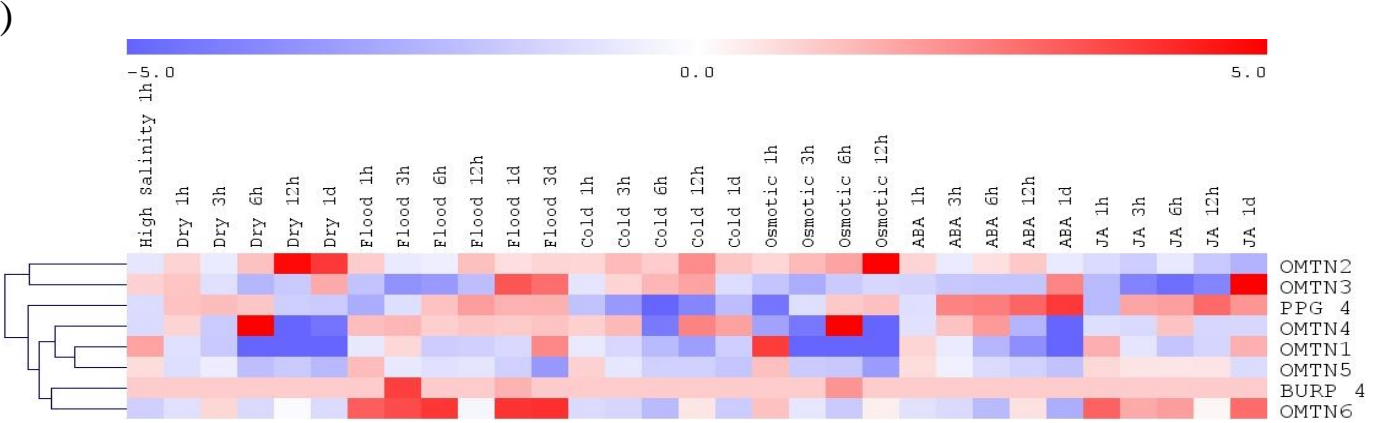

Figure 4. Heatmap representing expression pattern of osa-miR164 targeted genes in adverse environmental conditions in the root samples (A) and the shoot samples (B). 
On the other hand, in the shoot (Figure 4B), most of the NAC gene family were down regulated under drought, osmosis and ABA stress conditions, except OMTN2 that was differently up regulated. OSBURP04 up regulated in all stress conditions. $P P G 4$ down regulated in high salinity, dry, cold treatments, but up regulated in flood, osmotics stresses, ABA and JA treatments (Figure 4B).

Comparing the gene expression between the shoot and the root shows organ-specific opposite responses suggesting an organ-specific regulators. OMTN 1 up regulated in the root in all stresses, but down regulated in the shoot under many stresses. In the root, OMTN 2 up regulated in high salinity, down regulated in cold condition, but not in the shoot. OMTN 4 showed up regulation in high salinity, dry, osmotic, JA treatments and down regulation in cold condition in the root, but in the shoot the expression of OMTN 4 was in opposite direction. OMTN5 up regulated in all stresses in the root, but in the shoot its expression decreased in dry, flood, cold, osmotic and ABA treatments. On the contrary, OMTN 6 down regulated in all stresses in the root, but up regulated under flood and JA treatments in the shoot. PPG4 gene expression also showed opposite responses between the root and the shoot under high salinity, flood, ABA and JA treatments.

\section{Discussion}

MicroRNAs are small non-coding RNA molecules that play key roles in growth, development and stress responses of plants. The miRNAs function by selectively regulating the expression of specific target genes. Thus, identification of the potential target genes of miRNAs provides an effective way to investigate the complex mechanisms responsible for stress adaptation.

By using in silico bioinformatics approach in this study, we analyzed miRl64 family in rice. The sequences of mature osa-miRl64 $a / b / c / d / e / f$ are highly conserved as in agreement with the finding of Fang et al., [10], while the sequences of precursors are highly variable. The diversified sequences of miRl64 precursors might be of interest for designing primers for quantification of miRl64 gene expression levels, especially for osa-miRl64 a/b//f which were shown completely identical in sequences of the mature ones.

In order to understand how stress stimuli regulate the expression of osa-miRl64 genes, we analyzed the regulatory regions of osa-miR164 genes. The results show the different combinations of the cis-regulatory elements present in the promoter of each osa-miR164, suggesting the diverse expression pattern of osa-miRl64 genes in response to different environmental conditions. However, the expression data of osa-miRl64s in database is still limited, in which the expression levels of osa-miRl64a/b/f cannot be found separately (Figure 3). Some key cis-regulatory elements responsive for abiotic stress (DRE, MYC, MYB, etc.) and hormone related (GARE, ABRE, ARF) were found in osa-miRl64 gene promoters, indicating the functional roles of miR164 in stress responses of rice. In the previous study of Zhang et al., (2011), osa-miRl64 was shown to up-regulate under radiation stress [33]. The expression of miRl64 gene in response to salt stress is different between plant species, in which the up-regulation was observed in Arabidopsis thaliana [34] and Populus trichocarpa [35] but the down-regulation was found in Zea mays [36] and Panicum virgatum [37]. Previous study has reported that auxin signaling by miRl64 is important for normal lateral root development [8]. MiR164 expression was consistent with auxin level and its target NAC1 to regulate auxin signaling [38]. To our knowledge, this is the first report on the cis-regulatory elements of osa-miR164 genes.

In the previous research, Fang et al., (2014) showed that rice miRl64s target six NAC genes designated as OMTN1-OMTN6 and other 3 genes named OMT7-OMT9 [10]. In our study, we could find nine osa-miRl64 target genes, in which some of them had been reported to be involved in stress responses in rice such as genes encoding 
NAC-domain proteins (OMTN1-OMTN6), (Table 2 and references herein). The expression levels of osa-miR164 targeted genes under different stress conditions were variable between the root samples and the shoot samples and showed organ-specific opposite responses (Figure 4). Thus, it might be meaningful to carry out experiment to investigate the expression levels of osa-miR164 genes separately in the roots and in the shoots of rice plants.

Overall, rice miRl64 family has six gene members which are regulated by different stress related cis-regulatory elements and subsequently they regulate the expression of target genes involved in stress responses of rice plants. The in-depth understanding of the miRNA-guided regulation mechanisms responsible for stress may help unravel the regulatory networks of stress response and may also help in developing new strategies to manipulate rice plants with improved stress tolerance.

\section{Acknowledgements}

This work was financially supported by the L'Oréal-UNESCO For Women in Science National Fellowship.

\section{References}

[1] D. P. Bartel, C. Z. Chen, Micromanagers of Gene Expression: The Potentially Widespread Influence of Metazoan MicroRNAs, Nat, Rev, Genet, Vol. 55, No. 5, 2004, pp. 396-400, https://doi.org/10.1038/nrg1328.

[2] R. C. Lee, R. L. Feinbaum, V. Ambros, The C. elegans Heterochronic Gene Lin-4 Encodes Small RNAs with Antisense Complementarity to Lin-14, Cell, Vol. 75, 1993, pp. 843-854, https://doi.org/10.1016/0092-8674(93)90529-Y.

[3] B. J. Reinhart, E. G. Weinstein, M. W. Rhoades, B. Bartel, D. P. Bartel, MicroRNAs in Plants, Genes Dev, Vol. 16, 2002, pp. 1616-1626, https://doi.org/10.1101/GAD.1004402.

[4] J. C. Carrington, V. Ambros, Role of MicroRNAs in Plant and Animal Development, Science, Vol. 80, No. 301, 2003, pp. 336-338, https://doi.org/10.1126/SCIENCE.1085242.
[5] R. Simita, G. Thomas, P. Alexis, B. Thomas, L. Patrick, T. Klaus, Interplay of miR164, Cup-shaped Cotyledon Genes and Lateral Suppressor Controls Axillary Meristem Formation in Arabidopsis thaliana, Plant J, Vol. 55, 2008, pp. 65-76, https://doi.org/10.1111/J.1365-313X.2008.03483.X.

[6] G. Hui-Shan, X. Qi, F. J. Feng, C. N. Hai, MicroRNA Directs MRNA Cleavage of the Transcription Factor NAC1 to Downregulate Auxin Signals for Arabidopsis Lateral Root Development, Plant Cell, Vol. 17, 2005, pp. 376-386, https://doi.org/10.1105/TPC.105.030841.

[7] L. Patrick, P. Alexis, M. Halima, T. Jan, MicroRNA Regulation of the CUC Genes is Required for Boundary Size Control in Arabidopsis Meristems, Development, Vol. 131, 2004, pp. 4311-4322, https://doi.org/10.1242/DEV.01320.

[8] K. J. Hee, W. H. Ryun, K. Jeongsik, L. P. Ok, L. I. Chul, C. S. Hee, H. Daehee, N. H. Gil, Trifurcate Feed-forward Regulation of Age-dependent Cell Death Involving MiR164 in Arabidopsis, Science, Vol. 323, 2009, pp. 1053-1057, https://doi.org/10.1126/SCIENCE.1166386.

[9] R. Sunkar, X. Zhou, Y. Zheng, W. Zhang, J. K. Zhu, Identification of Novel and Candidate MiRNAs in Rice by High Throughput Sequencing, BMC Plant Biol, Vol. 81, No. 8, 2008, pp. 1-17, https://doi.org/10.1186/1471-2229-8-25.

[10] Y. Fang, K. Xie, L. Xiong, Conserved MiRl64-targeted NAC Genes Negatively Regulate Drought Resistance in Rice, J. Exp, Bot, Vol. 65, 2014, pp. 2119, https://doi.org/10.1093/JXB/ERU072.

[11] A. Kozomara, S. Griffiths-Jones, miRBase: Annotating High Confidence microRNAs using Deep Sequencing Data, Nucleic Acids Res, Vol. 42, 2014, pp. D68-D73, https://doi.org/10.1093/NAR/GKT1181.

[12] M. A. Larkin, G. Blackshields, N. P. Brown, R. Chenna, P. A. McGettigan, H. McWilliam, F. Valentin, I. M. Wallace, A. Wilm, R. Lopez, J. D. Thompson, T. J. Gibson, D. G. Higgins, Clustal $\mathrm{W}$ and Clustal X Version 2.0, Bioinformatics, Vol. 23, 2007, pp. 2947-2948, https://doi.org/10.1093/BIOINFORMATICS/BTM404.

[13] S. Kumar, G. Stecher, K. Tamura, MEGA7: Molecular Evolutionary Genetics Analysis Version 7.0 for Bigger Datasets, Mol, Biol, Evol, Vol. 3, 2016, pp. 1870-1874 https://doi.org/10.1093/MOLBEV/MSW054

[14] A. K. S. Gurjar, A. S. Panwar, R. Gupta, S. S. Mantri, PmiRExAt: Plant miRNA Expression Atlas Database and Web Applications, Database, 2016, https://doi.org/10.1093/DATABASE/BAW060. 
[15] K. Nakashima, Y. Ito, K. Y. Shinozaki, Transcriptional Regulatory Networks in Response to Abiotic Stresses in Arabidopsis and Grasses, Plant Physiol, Vol. 149, 2009, pp. 88-95, https://doi.org/10.1104/PP.108.129791.

[16] B. Mohanty, Promoter Architecture and Transcriptional Regulation of Genes Upregulated in Germination and Coleoptile Elongation of Diverse Rice Genotypes Tolerant to Submergence, Front, Genet, Vol. 0, 2021, pp. 235, https://doi.org/10.3389/FGENE.2021.639654.

[17] M. R. Khan, I. Khan, Z. Ibrar, J. Léon, A. A. Naz, Drought-responsive Genes Expressed Predominantly in Root Tissues are Enriched with Homotypic cis-regulatory Clusters in Promoters of Major Cereal Crops, Crop J, Vol. 5, 2017, pp. 195-206, https://doi.org/10.1016/J.CJ.2016.10.001.

[18] S. Labbé, M. M. O. Peña, A. R. Fernandes, D. J. Thiele, A Copper-sensing Transcription Factor Regulates Iron Uptake Genes in Schizosaccharomyces pombe, J. Biol, Chem, Vol. 274, 1999, pp. 36252-36260, https://doi.org/10.1074/JBC.274.51.36252.

[19] A. M. Nakashita, Y. Nakamura, A. W. Takahashi, E. Inoue, T. Yamaya, H. Takahashi, Identification of a Novel Cis-acting Element Conferring Sulfur Deficiency Response in Arabidopsis Roots, Plant J, Vol. 42, 2005, pp. 305-314, https://doi.org/10.1111/J.1365-313X.2005.02363.X.

[20] J. Li, G. Han, C. Sun, N. Sui, Research Advances of MYB Transcription Factors in Plant Stress Resistance and Breeding, Plant Signal, Behav, Vol. 14, 2019, https://doi.org/10.1080/15592324.2019.1613131.

[21] M. Mena, F. J. Cejudo, I. I. Lamoneda, P. Carbonero, A Role for the DOF Transcription Factor BPBF in the Regulation of Gibberellin-Responsive Genes in Barley Aleurone, Plant Physiol, Vol. 130, 2002, pp. 111-119, https://doi.org/10.1104/PP.005561.

[22] Y. Li, K. K. Lee, S. Walsh, C. Smith, S. Hadingham, K. Sorefan, G. Cawley, M. W. Bevan, Establishing Glucose- and ABA-regulated Transcription Networks in Arabidopsis by Microarray Analysis and Promoter Classification Using a Relevance Vector Machine, Genome Res, Vol. 16, 2006, pp. 414-427, https://doi.org/10.1101/GR.4237406.

[23] S. A. Sheshadri, M. J. Nishanth, B. Simon, Stress-mediated Cis-element Transcription Factor Interactions Interconnecting Primary and Specialized Metabolism in Planta, Front, Plant Sci, Vol. 0, 2016 , pp. 1725, https://doi.org/10.3389/FPLS.2016.01725.
[24] N. Kovalchuk, W. Wu, O. Eini, N. Bazanova, M. Pallotta, N. Shirley, R. Singh, A. Ismagul, S. Eliby, A. Johnson, P. Langridge, S. Lopato, The Scutellar Vascular Bundle-specific Promoter of the Wheat HD-Zip IV Transcription Factor Shows Similar Spatial and Temporal Activity in Transgenic Wheat, Barley and Rice, J. Plant Biotechnol, Vol. 10, 2012, pp. 43-53, https://doi.org/10.1111/J.14677652.2011.00633.X.

[25] G. J. A. Hernández, P. León, L. R. H. Estrella, Sugar and ABA Responsiveness of a Minimal RBCS Light-responsive Unit is Mediated by Direct Binding of ABI4, Plant J, Vol. 43, 2005, pp. 506-519, https://doi.org/10.1111/J.1365-313X.2005.02468.X.

[26] A. Morikami, R. Matsunaga, Y. Tanaka, S. Suzuki, S. Mano, K. Nakamura, Two Cis-acting Regulatory Elements are Involved in the Sucrose-inducible Expression of the Sporamin Gene Promoter from Sweet Potato in Transgenic Tobacco, Mol, Genet, Genomics, Vol. 2726, No. 272, 2005, pp. 690-699, https://doi.org/10.1007/S00438-004-1100-Y.

[27] F. Xu, X. H. Huang, L. L. Li, G. Deng, H. Cheng, X. F. Rong, J. B. Li, S. Y. Cheng, Molecular Cloning and Characterization of GbDXS and GbGGPPS Gene Promoters from Ginkgo biloba, Genet, Mol, Res, Vol. 12, 2013, pp. 293-301, https://doi.org/10.4238/2013.FEBRUARY.4.3.

[28] A. Rose, I. Meier, U. Wienand, The Tomato I-box Binding Factor LeMYBI is a Member of a Novel Class of Myb-like Proteins, Plant J, Vol. 20, 1999, pp. 641-652, https://doi.org/10.1046/J.1365313X.1999.00638.X.

[29] X. Ding, X. Hou, K. Xie, L. Xiong, Genome-wide Identification of BURP Domain-containing Genes in Rice Reveals a Gene Family with Diverse Structures and Responses to Abiotic Stresses, Planta, Vol. 2301, No. 230, 2009, pp. 149-163, https://doi.org/10.1007/S00425-009-0929-Z.

[30] J. Wang, Y. Long, J. Zhang, M. Xue, G. Huang, K. Huang, Q. Yuan, X. Pei, Combined Analysis and miRNA Expression Profiles of the Flowering Related Genes in Common Wild Rice (Oryza rufipogon Griff), Genes Genomics, Vol. 40, No. 8, 2018, pp. 835-845, https://doi.org/10.1007/s13258-018-0688-y.

[31] J. Zhang, K. Chen, Y. Pang, S. A. Naveed, X. Zhao, X. Wang, Y. Wang, M. Dingkuhn, J. Pasuquin, Z. Li, J. Xu. QTL Mapping and Candidate Gene Analysis of Ferrous Iron and Zinc Toxicity Tolerance at Seedling Stage in Rice by Genome-wide Association Study, BMC Genomics, Vol. 27, No. 18, 2017, pp. 828, https://doi.org/10.1186/s12864-017-4221-5. 
[32] Y. Tao, Y. Niu, Y. Wang, T. Chen, S. A. Naveed, J. Zhang, J. Xu, Z. Li. Genome-wide Association Mapping of Aluminum Toxicity Tolerance and Fine Mapping of a Candidate Gene for Nrat1 in Rice, PLoS ONE, Vol. 13, No. 6, 2018, pp. 0198589, https://doi.org/10.1371/journal.pone.0198589.

[33] M. Zhang, S. Liang, X. Hang, Y. Xiang, Z. Cheng, W. Li, J. Shi, L. Huang, Y. Sun, Identification of Heavy-ion Radiation-induced MicroRNAs in Rice, Adv, Sp, Res, Vol. 6, 2011, pp. 1054-1061, https://doi.org/10.1016/J.ASR.2010.10.024.

[34] B. B. Amor, S. Wirth, F. Merchan, P. Laporte, Y. A. Carafa, J. Hirsch, A. Maizel, A. Mallory, A. Lucas, J. M. Deragon, H. Vaucheret, C. Thermes, M. Crespi, Novel Long Non-protein Coding RNAs Involved in Arabidopsis Differentiation and Stress Responses, Genome Res, 19, 2009, pp. 57, https://doi.org/10.1101/GR.080275.108.
[35] B. Li, H. Duan, J. Li, X. W. Deng, W. Yin, X. Xia, Global Identification of miRNAs and Targets in Populus euphratica under Salt Stress, Plant Mol, Biol, Vol. 816, No. 81, 2013, pp. 525-539, https://doi.org/10.1007/S11103-013-0010-Y.

[36] D. Ding, L. Zhang, H. Wang, Z. Liu, Z. Zhang, Y. Zheng, Differential Expression of MiRNAs in Response to Salt Stress in Maize Roots, Ann, Bot, Vol. 103, 2009, pp. 29, https://doi.org/10.1093/AOB/MCN205.

[37] F. Xie, Q. Wang, R. Sun, B. Zhang, Deep Sequencing Reveals Important Roles of MicroRNAs in Response to Drought and Salinity Stress in Cotton, J. Exp, Bot, Vol. 66, 2015, pp. 789-804, https://doi.org/10.1093/JXB/ERU437.

[38] Q. Liu, Y. Q. Chen, Insights into the Mechanism of Plant Development: Interactions of MiRNAs Pathway with Phytohormone Response, Biochem, Biophys, Res, Commun, Vol. 384, 2009, pp. 1-5, https://doi.org/10.1016/J.BBRC.2009.04.028. 